\title{
Sistema Web para Apoio ao Processo de Editoração de Anais de Eventos para Publicação no Open Journal System 3
}

\author{
Ronaldo Alves Pereira Filho ${ }^{1}$, Rafael Dias Araújo ${ }^{1}$ \\ ${ }^{1}$ Faculdade de Computação - Universidade Federal de Uberlândia (UFU) \\ Monte Carmelo - MG - Brasil \\ ronaldo.alves.1997@gmail.com, rafael.araujo@ufu.br
}

\begin{abstract}
Publishing scientific event papers in proceedings is an arduous process, but essential for its correct and improved indexing. It is a process that involves different Information Systems whose information exchange is usually done manually. Thus, this work aims to propose a system of information systems to support the process of publishing event proceedings managed by the Journal and Event Management System (JEMS) and published in the Open Journal System (OJS), version 3. Preliminary results with a functional prototype show good acceptance by users and the potential to reduce the time spent in this process.
\end{abstract}

Resumo. A editoração de trabalhos de eventos científicos em formato de anais é um processo árduo, mas essencial para que sua indexação seja feita corretamente e com qualidade. É um processo que envolve diferentes Sistemas de Informação cuja troca de informação é feita, geralmente, de forma manual. Dessa forma, este trabalho visa propor um Sistema de Sistemas de Informação para suporte ao processo de editoração de anais de eventos gerenciados pelo Journal and Event Management System (JEMS) e publicados no Open Journal System (OJS), versão 3. Resultados preliminares com uso de um protótipo funcional mostram uma boa aceitação dos usuários e o potencial de reduzir o tempo gasto nesse processo.

\section{Introdução}

A comunicação científica representa o conjunto atividades associadas à produção, disseminação e uso da informação por membros da comunidade científica [Garvey and Griffith 1979]. Uma das formas de exercitá-la é por meio da participação e publicação de trabalhos em eventos ou encontros científicos, que buscam reunir diversas pessoas com interesses e objetivos em comum para discutir e compartilhar conhecimentos relacionados a uma determinada área de pesquisa [Targino 2000]. Essa tipo de publicação é feita por coleções de documentos chamadas de Anais (no inglês, Proceedings), que atualmente têm sido armazenadas de forma digital em sistemas especializados. Um dos possíveis sistemas que cumpre esse papel é o Open Journal System (OJS) [PKP 2001], que é um software de código aberto e a plataforma mais utilizada atualmente em todo o mundo para publicação de periódicos abertos. A SBC OpenLib (SOL) ${ }^{1}$ é um exemplo de uma biblioteca digital aberta, mantida pela Sociedade Brasileira de Computação (SBC), que utiliza o OJS 3 para armazenar anais de eventos (dentre outros tipos de publicação).

\footnotetext{
${ }^{1}$ https://sol.sbc.org.br/index.php
} 
A editoração de anais de eventos é uma etapa que acontece após a avaliação por pares e é um processo bastante árduo e trabalhoso para o responsável, geralmente chamado de Coordenador(a) de Publicações, que recupera os trabalhos aprovados do sistema utilizado na etapa anterior. Para que a indexação dos trabalhos seja feita corretamente e com qualidade, é necessário um conjunto de metadados que define cada um desses trabalhos. O que ocorre é que muitos sistemas utilizados para essa fase de gerenciamento, como o Journal and Event Management System (JEMS), possui um conjunto reduzido de metadados. Ademais, muitas vezes, os próprios autores preenchem incorretamente os metadados, ou deixam de preenchê-los, fazendo com que a indexação não reflita corretamente o trabalho publicado. Os arquivos precisam, ainda, ser submetidos ao sistema de publicações o que, geralmente, acontece de forma manual devido à falta de integração entre esses sistemas. Dessa forma, o objetivo principal deste trabalho é projetar e desenvolver um sistema Web para suporte ao processo de editoração de anais e manipulação de documentos XML (eXtensible Markup Language) de eventos gerenciados pelo JEMS e publicados no Open Journal System, versão 3. Assim, este trabalho lida com o desafio da construção de um Sistema de Sistemas de Informação (SoIS) [Boscarioli et al. 2017].

\section{Metodologia}

Este trabalho está fundamentado no método Design Science Research (DSR) [Hevner et al. 2004]. O framework DSR para SI instanciado neste trabalho contempla: (i) o ambiente, que envolve coordenadores de publicação de eventos científicos, autores de trabalhos, sociedades científicas representando uma organização, e a as bibliotecas digitais como tecnologia; (ii) a pesquisa, com um processo de busca da solução que envolve coordenadores de publicações e autores de artigos científicos como usuários finais e avaliação que consiste em uma abordagem mista (qualitativa e quantitativa), com a realização de estudos analíticos acerca da estrutura e características do software e as interações realizadas no artefato proposto e avaliação em cenários reais; e (iii), a base de conhecimento, que está fundamentada em bibliotecas digitais para publicação de documentos científicos e na interoperabilidade de sistemas.

Em um primeiro momento, foram realizadas reuniões com dois coordenadores de publicação de eventos promovidos pela SBC com experiência de mais de quatro anos com o processo de editoração de anais. O processo foi modelado para definição das atividades executadas pelo sistema. Foi desenvolvido um protótipo funcional de maneira iterativa e incremental para realização de uma prova de conceito com usuários reais. Para desenvolver o sistema proposto foi utilizado o Sistemas Gerenciador de Banco de Dados MySQL, Python para escrita de cabeçalho e rodapé nos PDFs, HTML5, CSS3 e JavaScript para a interatividade da página e linguagem PHP e Composer - gerenciador de dependências do PHP - para a utilização bibliotecas específicas: CoffeeCode/DataLayer para acesso às entidades do banco de dados; CoffeeCode/Router para definir as rotas do sistema; e PHPOffice/PhpSpreadsheet para extrair informações de planilhas.

Foi realizada uma avaliação com autores de 192 artigos científicos publicados em um dos eventos promovidos pela SBC, que responderam a um questionário on-line com sete afirmativas referente à percepção de utilidade da ferramenta em uma escala Likert de 5 pontos ("Discordo totalmente" a "Concordo totalmente") e uma questão discursiva para sugestões e críticas. Após a avaliação, ajustes na implementação foram realizados para contemplar problemas enfrentados pelos usuários. 


\section{Resultados Preliminares e Discussões}

A Figura 1 apresenta um Diagrama de Atividades que mostra o processo de editoração modelado neste trabalho com o uso do sistema proposto. $\mathrm{O}$ ator "coordenador de publicações" efetua a configuração do volume desejado e suas respectivas seções. Em seguida, realiza a importação dos metadados iniciais dos artigos aceitos para publicação por meio de uma planilha eletrônica para cada seção (neste estudo, esses metadados foram recuperados do JEMS). Uma vez importados, uma interface é liberada aos autores para complementação e atualização dos metadados de seus artigos e geração do arquivo de metadados para ser submetido via JEMS. Findado o prazo dos autores, o(a) coordenador(a) continua o processo com a busca dos arquivos (versão final do artigo e arquivo de metadados) do JEMS e, se for o caso, configura o texto a ser escrito no cabeçalho e rodapé dos artigos (nome do evento, nome do volume, DOI e número de páginas) pelo sistema. Por fim, o XML completo do volume no formato OJS 3 pode ser gerado, contendo os metadados do volume e de cada artigo, incluindo o PDF codificado no formato base64.

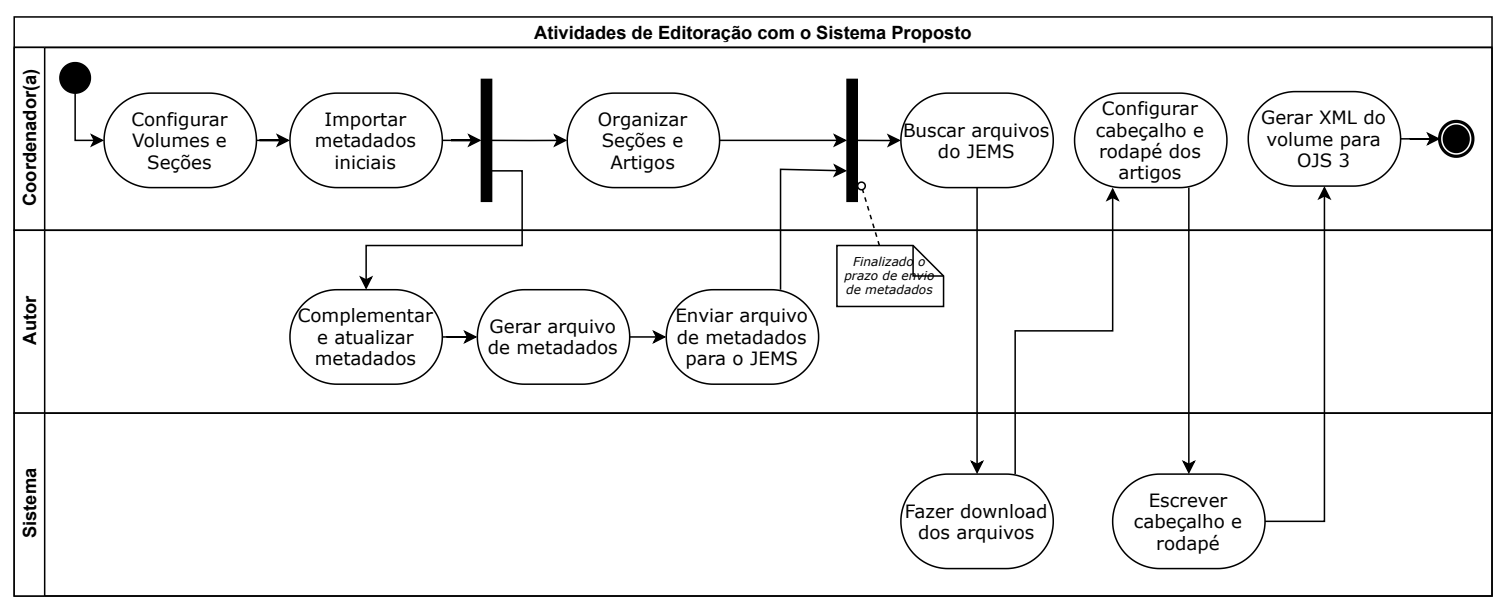

Figura 1. Diagrama de atividades do processo de editoração com o sistema.

A Tabela 1 sumariza as respostas dos autores ao questionário de avaliação após a utilização do sistema no primeiro ciclo de avaliação. No geral, é possível observar que os resultados se mostraram positivos com relação à percepção de utilidade e facilidade de uso do sistema proposto. Também é importante notar que os autores entendem a importância de preencher corretamente os metadados do artigo. Na pergunta discursiva para sugestões e críticas observou-se elogios quanto a proposta e foi possível identificar algumas dificuldades enfrentadas pelos autores quanto ao preenchimento dos metadados, como: ( $i$ ) entendimento do botão 'finalizar'; (ii) acesso aos metadados de um artigo; e, (iii) entendimento no preenchimento do campo de referências. O item (i) foi corrigido com a criação de um botão específico para salvar os metadados e um novo passo posterior (nova página) para informar que a atualização foi realizada com sucesso e para efetuar o download do arquivo de metadados. Para facilitar, também foi adicionado um botão para abrir o local específico no JEMS para fazer o upload do arquivo. A dificuldade do item (ii) aconteceu pelo fato de que o acesso aos metadados do artigo acontece por meio do número do artigo no JEMS e o endereço de e-mail do primeiro autor cadastrado no JEMS como senha. Acontecem casos em que os autores alteram a ordem de autoria na versão final, mas o JEMS não permite que os autores façam essa alteração, causando, então, confusão de quem realmente seria o primeiro autor nesse caso. Para minimizar o problema, 
foi colocada uma explicação mais detalhada na página de acesso. Como trabalhos futuros, também é possível incluir os e-mails de todos os autores para o acesso. Por fim, visando resolver a dificuldade no preenchimento do campo das referências, item (iii), foi criada uma janela modal com um exemplo de preenchimento. O arquivo XML contendo o volume completo foi, então, importado na biblioteca SOL e os artigos publicados.

Tabela 1. Sumarização das respostas ao questionário de avaliação dos autores.

\begin{tabular}{|l|c|c|c|}
\hline Afirmativas & Concorda* & Não sabe & Discorda* \\
\hline Eu consegui acessar os metadados do artigo facilmente & $97,4 \%$ & $0,5 \%$ & $2,1 \%$ \\
\hline Eu consegui atualizar os metadados do artigo facilmente & $94,3 \%$ & $2,6 \%$ & $3,1 \%$ \\
\hline Eu não tive dúvidas quanto ao preenchimento dos metadados & $90,1 \%$ & $1,6 \%$ & $8,3 \%$ \\
\hline $\begin{array}{l}\text { As instruções para o preenchimento dos metadados foram sufi- } \\
\text { cientes }\end{array}$ & $96,4 \%$ & $1,5 \%$ & $2,1 \%$ \\
\hline $\begin{array}{l}\text { Eu acho que a utilização dessa ferramenta é um trabalho difícil } \\
\text { para os autores }\end{array}$ & $17,2 \%$ & $6,3 \%$ & $76,5 \%$ \\
\hline Eu não vejo ganho no preenchimento dos metadados solicitados & $16,1 \%$ & $19,3 \%$ & $64,6 \%$ \\
\hline $\begin{array}{l}\text { Como autor, eu não me importo em utilizar a ferramenta para } \\
\text { garantir a correta publicação dos metadados do(s) meu(s) artigos }\end{array}$ & $75,0 \%$ & $2,6 \%$ & $22,4 \%$ \\
\hline
\end{tabular}

* Total ou parcialmente.

\section{Considerações Finais}

Este trabalho apresentou uma proposta de sistema Web para suporte ao processo de editoração de anais de eventos gerenciados pelo JEMS e publicados no OJS, versão 3. Foi realizada uma avaliação com autores de artigos científicos publicados em um dos eventos promovidos pela SBC e os resultados mostraram uma boa aceitação dos usuários, bem como a viabilidade da proposta para solucionar o problema da falta de metadados necessários para a correta indexação dos documentos e a minimização da dificuldade do processo de editoração de anais, gerando um único arquivo XML para a importação no OJS. As próximas etapas deste trabalho incluem ajustes na interface de metadados para evitar problemas de preenchimento pelos usuários, a melhoria da interface gerencial realizada pelo(a) Coordenador de Publicações e sua validação com o público-alvo.

\section{Agradecimentos}

Os autores deste trabalho agradecem o apoio da FACOM/UFU e da SBC, por meio da sua diretoria de publicações, que forneceu informações relevantes para o trabalho.

\section{Referências}

Boscarioli, C., Araujo, R. M., and Maciel, R. S. P. (2017). I Grand Research Challenges in Information Systems in Brazil 2016 - 2026. SBC, 1 edition.

Garvey, W. D. and Griffith, B. C. (1979). Communication and information process within scientific disciplines, empirical findings for psychology. In Garvey, W. D., editor, Communication: the essence of science; facilitating information among librarians, scientists, engineers and students. Oxford: Pergamon.

Hevner, A., March, S. T., Park, J., and Ram, S. (2004). Design science in information systems research. MIS Quarterly, 28(1):75-105.

PKP (2001). Open Journal Systems - Public Knowledge Project. Acessado em 30/09/2020.

Targino, M. d. G. (2000). COMUNICAÇÃO CIENTÍFICA: uma revisão de seus elementos básicos. Informação \& Sociedade: Estudos, 10(2). 